\title{
Abdominal Wall Endometrioma in Previous Cesarean Section Scar: Case Report
}

\begin{abstract}
Jiménez-Canet Atilano Alejandro1*, Pompa-de la Rosa Cayetano², Bizueto-Rosas Héctor², Pérez-González Hugo Alonso³, Magaña-Salcedo Jaime Roberto4, Echeverry-Fernández Camilo, Gutiérrez-Olivares Omar Marino ${ }^{1}$, Buendía-García Ana Laura ${ }^{1}$, Mijangos-Montaño Ared ${ }^{4}$, González-López Annel Ivonne ${ }^{4}$, Caltenco-Solis Raúl Beder ${ }^{4}$, Radilla-Flores Mariana ${ }^{4}$, Torrejón-Hernández Carlos Adrián ${ }^{4}$, Hidalgo-Delgado Jesús Nicolás ${ }^{4}$, Ramírez-Landeros Joshua ${ }^{4}, G^{2}$ Goa-Ramírez Fernando $^{4}$
\end{abstract}

${ }^{1}$ Senior Resident, Department of General Surgery, Instituto de Seguridad y Servicios Sociales de los Trabajadores del Estado, México

${ }^{2}$ Specialist, Department of General Surgery, Instituto de Seguridad y Servicios Sociales de los Trabajadores del Estado, México

${ }^{3}$ Specialist, Department of Vascular Surgery, Hospital General Regional Querétaro, Instituto de Seguridad y Servicios Sociales de los Trabajadores del Estado, México

${ }^{4}$ Resident, Department of General Surgery, Hospital General Dr. Darío Fernández Fierro, Instituto de Seguridad y Servicios Sociales de los Trabajadores del Estado, México

* Corresponding author: Jiménez-Canet Atilano Alejandro, Specialist, Department of General Surgery, Instituto de Seguridad y Servicios Sociales de los Trabajadores del Estado, México, E-mail: ciruddff@gmail.com

Received: 12 Apr, 2019 | Accepted: 28 Apr, 2019 | Published: 30 Apr, 2019

Citation: Jiménez-Canet AA, Pompa-de IRC, Bizueto-Rosas H, Pérez-González HA, Magaña-Salcedo JR, et al. (2019) Abdominal Wall Endometrioma in Previous Cesarean Section Scar: Case Report. J Surg Open Access 5(2): dx.doi.org/10.16966/2470-0991.180

Copyright: (C) 2019 Jiménez-Canet AA, et al. This is an open-access article distributed under the terms of the Creative Commons Attribution License, which permits unrestricted use, distribution, and reproduction in any medium, provided the original author and source are credited.

\section{Abstract}

Endometriosis is defined as the presence of functional endometrial tissue, glands and stroma outside the uterine cavity, mainly at ovaries and at pelvic peritoneum, causing a chronic inflammatory reaction. The abdominal wall endometrioma is an infrequent pathology; occurs after abdominal surgery, by minimal invasion, open surgery or gin-obs surgery. It happens in about 0.03 to $1.5 \%$ women after having a cesarean section, presenting transvaginal bleeding, endometrial ultrasound with $9 \mathrm{~mm}$ thickness and uterine myomatosis, having a painful node at the infra-umbilical abdominal scar, with skin colour change and due to increasing pain is diagnosed with an incarcerated hernia. Urgent surgery was performed, finding a $6 \times 6 \times 4$ $\mathrm{cm}$ vesicle, with brownish secretion, attached to the muscular aponeurosis.

Conclusion: Not every node or bulge within the abdominal wall should be considered hernia. in the scenario of a painful node and skin colour change at a surgical scar, with a medical history of cesarean section, hysterectomy and laparoscopic procedures, diagnosis of endometriosis should be considered and therefore always perform histopathological exams.

Keywords: Endometriosis; Abdominal wall; Cesarean section

\section{Introduction}

Endometriosis is defined as the finding of functional endometrial glands and tissue outside of the uterine cavity, in or outside the pelvis, mainly at ovaries and at pelvic peritoneum surface, which causes a chronic inflammatory reaction [1]. The presence of ectopic endometrial tissue has been reported not only at ovaries but also within urological organs, epiplon, bowel, lymph nodes, lungs, pleura, subarachnoid space, limbs, belly button, kidneys, brain, liver, pericardium, episiotomies and surgical scars [2]. Extrapelvic presentation is infrequent; regarding the presentation within cesarean section scar, its incidence varies from 0.03 to $1.7 \%$.

Abdominal wall endometriosis is presented as a painful node within the thickness of a surgical scar due to cesarean section, hysterectomy, myomectomy, episiotomy or even smaller laparoscopic procedures [3]. They are some theories to explain the origin of endometriosis: a) metastatic, in which the endometrial mucosa reaches an ectopic extrauterine location by several transport routes such as the coelomic, lymphatic, by the fallopian tube, by blood or iatrogenic.

The iatrogenic pathway happens by the transport of endometrial tissue with surgical material at urological or gynecological procedures, can explain endometriosis at surgical scars, at the abdominal wall or at episiotomy. In the metaplasic via, the endometrial ectopic tissue originates directly from the tissue with the ability to mutate to different tissue lines of growth. At the immunological pathway, the patients with endometriosis have a decreased number of T-lymphocytes mediating cytotoxicity against autologous endometrial cells and a decrease in the ability of lymphocyte response against endometrial antigens.

Some studies attribute to estrogens an etiological role in the development of endometriosis since this pathology is almost exclusive of women in reproductive age [4]. 
Given that the abdominal tumor is present in more than $90 \%$ of the patients and it is related to the menstrual cycle, it is important an adequate anamnesis due to the similarities with abdominal wall endometriosis and others like an incisional hernia, granuloma, allergic reactions, abscess, lipoma, sarcoma or metastasis [5-7]. When the ectopic endometrial tissue presents as a well-defined tumor is called endometrioma or endometriosis granuloma [8]. This lesions when superficial can ulcer and be misdiagnosed with oncological entities, being necessary other procedures to correctly diagnose and determine the extent of it or exclude another intra-abdominal concomitant pathology $[9,10]$

In most cases, the endometrioma of the surgical incision develop in the first 6 months after surgery, however, cases that occurred at 10 years have been reported, although in most patients, they manifest around 1 or 2 years later. Endometriosis of the inguinal canal is very rare, being related to implants of endometrial tissue in the round ligament. The differential diagnosis in these cases is established with inguinal hernia, however, they present inguinal pain in relation to the menstrual cycle [4].

Malignant tumors that grow from endometriosis occur in approximately $0.3-0.8 \%$ of cases of ovarian endometriosis, there are no definitive studies about the presence of malignant tumors in endometriotic foci of the abdominal wall, it has been reported up to $4.1 \%[4]$.

The treatment of choice is always the total removal of the lesion, sometimes requiring the placement of prosthetic meshes or the abdominal wall plasty with the rotation of a musculoaponeurotic flap [6]. Medical treatment with the use of progestogens, contraceptives oral and/or danazol is not effective and produces only partial relief of symptoms.

The recurrence is an average of $4.5 \%$ or as high as $12 \%$ as reported by Cárdenas-Lailson LE, et al [6].

\section{Case Report}

26 years old female, medical history of cesarean section 5 years previous and last month requiring a uterine curettage due to incomplete abortion. After abortion presents transvaginal bleeding and a gynecologic ultrasound was performed with the findings of abnormal secretor endometrium, with $9 \mathrm{~mm}$ thickness and uterine myomatosis.

A week prior to her admission presents a painful node at the abdominal midline scar (cesarean section), size increasing, colour changes, and more symptoms in the last 24 hours, without history of fever or intestinal symptoms. At clinical review at abdominal midline scar with a palpable tumor of $3 \times 2 \mathrm{cms}$ in the upper third, colour changes by a purplish center and hyperemia, painful, non-reducible and without abdominal signs. Plan X-ray being normal and blood test without changes.

Initial diagnose being incarcerated haernia vs. abdominal wall granuloma.

Surgical laparotomy by midline approach was performed. Initially, the previous scar was resected, at subcutaneous tissue, a tumor of $6 \times 6 \times 4 \mathrm{cms}$ (Figure 1) was found firmly adhered to the anterior aponeurosis, with several fibrous tissue and vesicles with brownish secretion. Anterior aponeurosis was found complete and integrate but with a small thinned zone so a suture plication was performed with polypropylene stitches. The resected piece was sent to culture and histopathological definite analysis.

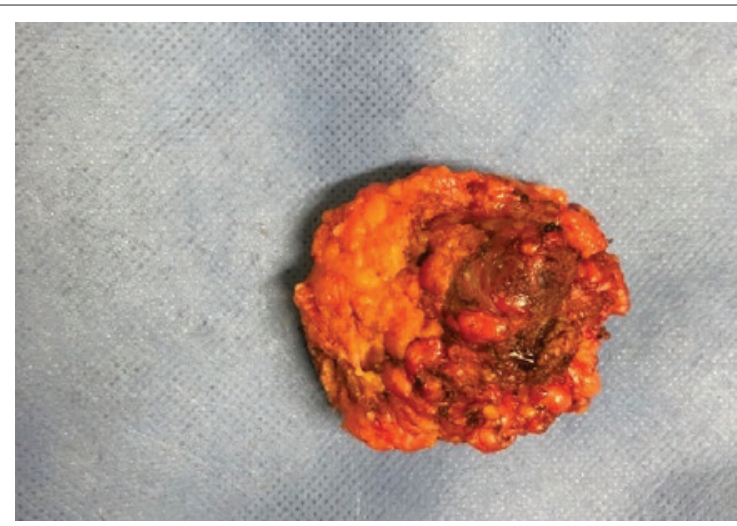

Figure 1: Surgical specimen of abdominal wall.

After surgery with good postoperative evolution, she was discharged within 24 hours.

In medical office follow-up, the definitive histopathological result confirms "endometriosis", with chronic granulomatous inflammatory reaction, and giant cell reaction to foreign body, probable hemosiderin (Figures 2 and 3).

After 2 months during office follow-up, the patient showed good recovery, no abdominal pain, and full cicatrization of surgical injury and without local complications. Follow-up by the Gynecology service required initial treatment with progestagens to avoid recurrence and after two years has not presented menstrual abnormal pain, abdominal tumor or scar node.

\section{Discussion}

Abdominal wall endometrioma is an under diagnosed entity by the Surgeons due to little clinical suspicion [3], it represents a challenge to the General Surgeon due to a great similarity of signs and symptoms with other diseases and tumors. Cárdenas-Lailson LE, et al. [6] state that abdominal wall endometriomas are not usually considered as a differential diagnosis in women with painful, a palpable node at a surgical abdominal scar due to its low frequency and very similar clinical findings with incisional hernia. Endometriomas have a macroscopical appearance of "brownish-chocolate cyst". Ultrasound imaging of endometrioma usually is characteristic and non-mistakable, with a single or multilocular node, homogeneous eco within and a cyst of thickened walls but with different grades of echogenicity at different lobes. To establish the initial diagnosis it usually requires a medical history of endometriosis with histologically confirmatory analysis due to up to $50 \%$ of women with previous endometriosis usually forms endometriomas, and a posterior definite histological confirmatory analysis is required [11].

Endometriosis is present in between $0.03-0.47 \%$ of cesarean section scars. Most of the cases have a medical history of complicated incisional hernia, however, an important percentage has abdominal wall endometrioma, with a foreign body reaction to surgical suture is the main cause. Treatment of choice is the complete resection of the lesion, with wide edges [2].

It is frequent that the node or lesion is firmly adhered to anterior aponeurosis, requiring the resection of an aponeurosis segment in order to resect the complete lesion [5].

It is recommended that a healthy edge is left to diminish recurrence, which presents up to $4.3 \%$ of the cases [6-12]. In most cases, complete resection is considered the definitive treatment [3-6]. 


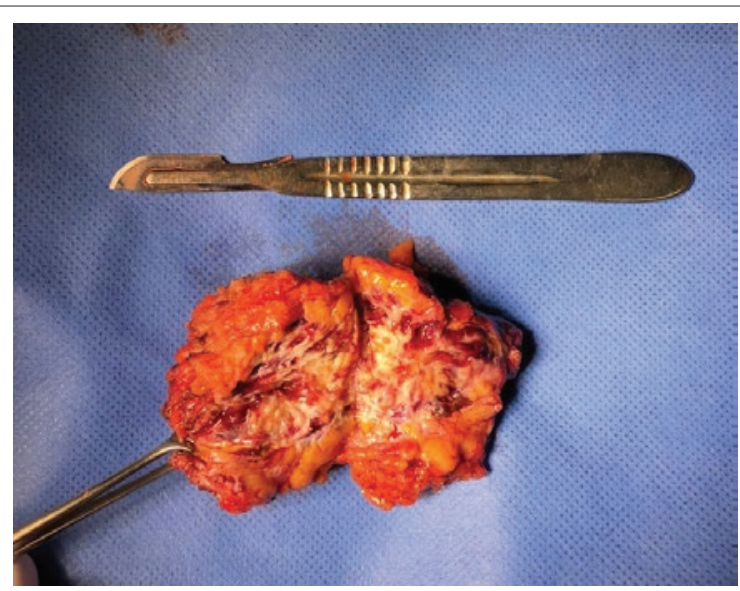

Figure 2: Surgical obtained piece after sagittal cut: Fibrous tissue and brownish secretion vesicles are observed with probable diagnosis of granuloma.

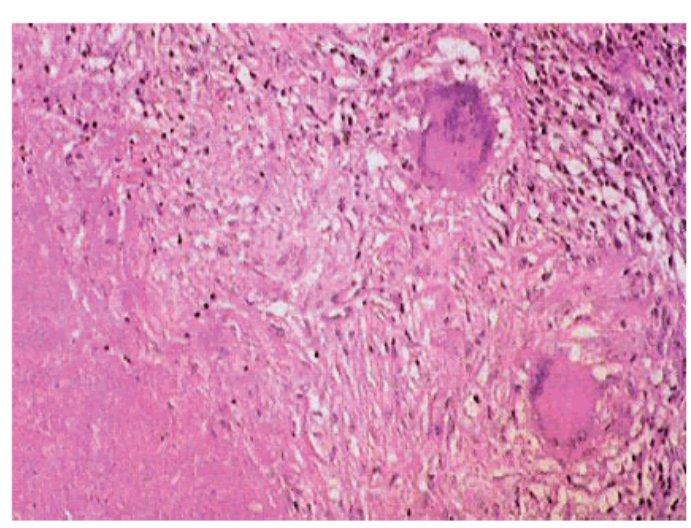

Figure 3: After hematoxylin and eosin dye, and 10X view. Granulomatous lesion with epithelioid cells and multinucleated giant cells without atypia. Mononuclear inflammatory cells and bleeding recient zones with hemosiderosis.

In ovarian endometriomas, recurrence can be diminished by contraceptive treatment from $25 \%$ to $9-15 \%$, depending on medication choice [12].

Abdominal wall endometrioma when obstetric hysterectomy is required depends on the gestation trimester; at the $2^{\text {nd }}$ trimester incidence is $1.08 \%$, in the $3^{\text {rd }}$ trimester is $0.03 \%$ [2].

Endometriomas, also known as Pfannenstiel syndrome, is formed by endometrioma implants previously existent at the abdominal cavity, and then disseminated to the abdominal wall scars according to different theories: direct transplant or implantation, direct extension (Cullen), extension by lymph or blood (Halban).

Abdominal wall endometrioma has an incidence of 14.3 to $26 \%$, with carcinomatosis association in 0.3 to $1 \%$ [2,9]; with findings of enolase specific protein, being a specific neuroectoderm-tissue protein [12]. Abdominal wall endometrioma has been reported in 14.3 to $26 \%$, with an incidence of carcinoma reported between 0.3 to $1 \%[2,9]$. Despite the gynecological and obstetrical history of our patient, the differential diagnosis was suspected by the surgical findings, confirming the underestimation of this pathology, as reported previously.

\section{Conclusion}

Abdominal wall endometrioma is low-incidence pathology in our population; however, a higher suspicious rate is needed in younger, age-reproductive women, with a medical history of abdominal surgery either gynaecological or obstetrical. Clinical manifestation can be several years after surgery and also has to be considered as differential diagnosis in order to establish a definitive treatment, being wide and complete node resection. Echographic findings of endometriomas are almost associated with endometriosis, but no-echographic findings can't discard it.

\section{References}

1. GPC (2015) Diagnóstico y tratamiento de la endometriosis.

2. Carvajal MA, Braghetto-MI, Carvajal GR, Miranda VC (2007) Endometriosis de la pared abdominal. Rev Chil Obstet Ginecol 72: 105-110.

3. Pardo MI, Campos S, Ouviña O, Caramés N, Vidal R, et al. (2010) Endometriosis en cicatriz de cesárea anterior. Clin Invest Gin Obst 37: 35-37.

4. González-Santín V, Robres J, Farreras N, Ortiz de Zárate L, Buqueras C, et al. (2008) Endometriomas de la pared abdominal. Revisión de una serie de 17 casos. Clin Invest Gin Obst 35: 2-6.

5. Eljuga D, Klarić P, Bolanča I, Grbavac I, Kuna K (2012) Abdominal wall endometriosis: case report. Acta Clin Croat 51: 261-263.

6. Cárdenas-Lailson LE, Berlanga-Ramírez F, Athié-Athié AJ, GonzálezParada F, Villanueva-Egan LA (2002) Endometrioma de pared abdominal: Características clínicas y resultados del tratamiento quirúrgico. Cirujano General 24: 295-299.

7. Blanco RG, Parithivel VS, Shah AK, Gumbs MA, Schein $M$, et al. (2003) Abdominal wall endometriomas. Am J Surg 185: 596-598.

8. Firilas A, Soi A, Max M (1994) Abdominal incision endometriomas. Am Surg 60: 259-261.

9. Zhao X, Lang J, Leng J, Liu Z, Sun D, et al. (2005) Abdominal wall endometriomas. Int J Gynaecol Obstet 90: 218-222.

10. Gunes M, Kayikcioglu F, Ozturkoglu E, Haberal A (2005) Incisional endometrosis after cesarean section, episiotomy and other gynecologic procedures. J Obstet Gynaecol Res 31: 471-475.

11. Restrepo CGA (2010) Endometriosis, endometrioma e infertilidad. Rev Med 18: 197-209.

12. Martínez DG, Romano RC, Sánchez AW, Horcasitas LM (2008) Dificultad diagnóstica del endometrioma de pared abdominal: caso clínico y revisión de la bibliografía. Ginecol Obstet Mex 76: 125-130. 